B.G. Saneev

Melentiev Energy Systems Institute of Siberian Branch of the Russian Academy of Sciences, Irkutsk, Russian Federation

A.D. Sokolov

Melentiev Energy Systems Institute of Siberian Branch of the Russian Academy of Sciences, Irkutsk, Russian Federation

S.Yu. Muzychuk

Melentiev Energy Systems Institute of Siberian Branch of the Russian Academy of Sciences, Irkutsk, Russian Federation

R.I. Muzychuk Melentiev Energy Systems Institute of Siberian Branch of the Russian Academy of Sciences, Irkutsk, Russian Federation

\title{
GROWTH OF ENERGY EFFICIENCY IS THE ROAD TO SUSTAINABLE DEVELOPMENT OF ECONOMY OF RUSSIA'S EASTERN REGIONS
}

\begin{abstract}
The Russian fuel-energy complex (FEC) is the basis without normal functioning of which the sustainable development of economy is made impossible; especially impressive it is revealed in the east of the country where the FEC sectors contribute most significantly to the industrial production. Besides, the diversification of the export flows of the fuel and energy resources (FER) considerably increases the role of the eastern direction in Russia's economic policy. All this determines the topicality of studying the processes of FEC development in the eastern regions (Siberia and the Far East) using mathematical modelling. The purpose of investigation is to carry out an energy-economic analysis, identification of FEC development problems in the eastern regions and specifying the main ways to overcome them. The research methods are system analysis, economic and mathematic modelling and indicative methods. Results of the study: on the basis of the available statistic information the fuel-energy balances (FEB) of the Russia's eastern regions have been developed, an analysis of the FEC current state has been made, the main problems of its development have been identified, the most important factors that impact the energy efficiency of economy have been determined, using the model tools the long-term FEC development forecast has been carried out. The conclusions: the current state of the eastern regions' FEC allow to provide the economy with necessary quantity of FER, yet the problems exist that limit the FEC development which can hinder the economy to develop massively. It is necessary to implement the measures that provide the energy efficiency in all spheres of economic activity, as well as to change the structure of the FEB in Russia's eastern regions in the direction of more rational use of the fuel and energy resources ( FER) and to scale up the introduction of of technological innovations, all this will allow to increase the energy efficiency of the economy.

KEYWORDS. Economic and mathematical modelling, system analysis, development, eastern regions, energy consumption, fuel and energy balance.

ARTICLE INFO. Received May 22, 2019; accepted June 21, 2019; available online July $15,2019$.

FUNDING. The article was prepared with the financial support of the research project of the Siberian Branch of the Russian Academy of Sciences No. 0349-2016-0014, No. of State. registrations AAAA-A17-117030310445-9.
\end{abstract}

\section{Введение}

Российский ТЭК формирует около 30 \% валового внутреннего продукта (ВВП) страны, 50 \% доходов бюджета и почти 70 \% экспортного потенциала России [1].

\section{Baikal Research Journal}


Развитие ТЭК должно обеспечивать рост эффективности и конкурентоспособности российской экономики. Большую роль в этом играет повышение энергоэффективности, которое является ресурсом, позволяющим без роста производства топлива и энергии обеспечивать увеличивающиеся потребности экономики и жилищно-коммунального хозяйства (ЖКХ).

Основной показатель энергоэффективности страны - энергоемкость валового внутреннего продукта (ВВП). Россия по этому показателю значительно уступает развитым странам мира, например, США - в 1,6 раза, Японии - в 2,2 раза, Швейцарии - в 3,7 раза ${ }^{1}$. Зачастую в России при производстве одинаковой продукции затрачивается больше материальных, трудовых и финансовых ресурсов, чем в станах с развитой экономикой. Повышенные (по сравнению с мировыми аналогами) удельные расходы ТЭР при производстве промышленной продукции приводят к ухудшению экологии, увеличению темпов освоения месторождений топливно-энергетических полезных ископаемых, к их ускоренному истощению. Поэтому энергосбережение и рост энергоэффективности является важнейшим приоритетом государственной энергетической политики и социально-экономического развития в России и ее регионах.

Из-за высокоэнергоемкой отраслевой специализации и климатических особенностей, для восточных регионов России рост энергоэффективности экономики еще более актуален, чем для страны в целом и ее западных регионов. Показатели энергоемкости валового регионального продукта (ВРП) восточных регионов в 2-3 раза выше, чем в среднем по стране, это обусловливает необходимость разработки специальных методов и моделей изучения процессов развития ТЭК для повышения эффективности использования топливно-энергетических ресурсов.

В качестве основного метода исследования использовался системный анализ ТЭК. Для этого разработаны ретроспективные топливно-энергетические балансы восточных регионов (за период 2005-2017 гг.), которые показывают движение потоков топливно-энергетических ресурсов от их добычи (производства) до конечного потребления. Анализ ТЭБ позволяет определить эффективность использования ТЭР в регионах. Для разработки прогнозных балансов используются методы экономико-математического моделирования, которые позволяют дать оценку энергоэффективности экономики восточных регионов при изменении условий развития ТЭК (для разных сценариев).

Для проведения исследований развития ТЭК восточных регионов России авторами используется информационно-вычислительный комплекс, состоящий из системы экономико-математических моделей: балансов отдельных видов энергоресурсов, сводных топливно-энергетических балансов восточных регионов, энергоэкономического и статистического анализа региональных ТЭБ $[2 ; 3]$.

\section{Степень проработанности темы}

В России начало исследованию ТЭК, проблем энергосбережения и энергоэффективности экономики с использованием топливно-энергетических балансов было положено в 1930-е гг. Г.М. Кржижановским, В.И. Вейцем, Е.А. Русаковским, А.Е. Пробстом [4; 5], для условий централизованно планируемой экономики продолжено в 1960-1980 гг. Л.А. Мелентьевым, М.А. Стыриковичем, А.С. Некрасовым, В.А. Янпольским, А.А. Макаровым и др. [6-8]. В ХXI в. исследования для условий рыночной экономики были развиты многими российскими учеными И.А. Башмаковым, В.В. Бушуевым, А.А. Троицким, Т.М. Галиевой, А.М. Мастепановым, В.Н. Чурашевым, Н.И. Сусловым и др. [9-14]. Однако эти разработки

\footnotetext{
${ }^{1}$ По данным MЭА. URL: http://energyatlas.iea.org/\#!/tellmap/-297203538/3.
}

\section{Baikal Research Journal}

электронный научный журнал Байкальского государственного университета 
в большей степени касались программ развития отдельных отраслей ТЭК и не отражали вопросы комплексного повышения энергоэффективности экономики. Задача формирования на основе системной методологии комплексных долгосрочных программ повышения энергоэффективности (федеральных и региональных) в рыночных условиях оставалась нерешенной.

Вопросы оптимального использования энергетических ресурсов и анализа энергоэффективности экономики в различных условиях развития капиталистического общества исследовались выдающимися зарубежными учеными-экономистами с 1930-х гг. по настоящее время (А. Розенфельд, М. Паттерсон, Р. Хаас, Х. Хотеллинг, Р. Солоу, В. Нордхаус, Ч. Морзе, Т. Лакшманан, С. Ратик, Г. Герринг, С. Соррель и др.) [15-23], которые разработали основные элементы методологии формирования комплексных программ повышения энергоэффективности в различных странах мира.

Для каждой страны или ее региона, в определенных условиях развития экономики задача роста ее энергоэффективности решается специально разработанными для этого методами, имеющими свою научную и практическую значимость, но существует ряд нерешенных вопросов, касающихся моделирования влияния отдельных факторов на энергоемкость ВРП, например, авторами проведены исследования по оценке влияния производства первичных ТЭР, их вывоза (экспорта) и затрат на технологические инновации на энергоемкость ВРП восточных регионов. Кроме того, каждый регион России имеет свою специфику, учет которой возможен только при индивидуальном подходе к прогнозированию развития ТЭК.

\section{Постановка задачи}

Российский ТЭК - это межотраслевой комплекс, связывающий производителей, поставщиков и потребителей топливно-энергетических ресурсов. Полную картину состояния ТЭК можно увидеть из сводного топливно-энергетического баланса, который объединяет отдельные балансы производства и потребления различных видов энергоресурсов (уголь, нефть, природный газ, нефтепродукты, электроэнергия, теплоэнергия и др. $)^{2}$.

Целью данного исследования является проведение энергоэкономического анализа восточных регионов на основе ТЭБ, выявление имеющихся в ТЭК проблем, разработка основных направлений его развития с учетом роста энергоэффективности экономики, который позволяет: более рационально использовать потенциал ТЭК, производить необходимые топливно-энергетические ресурсы с меньшими затратами, производить продукцию в отраслях экономики с меньшей энергоемкостью, снизить антропогенную нагрузку на экологию, что повысит качество жизни населения.

Развитие отраслей ТЭК в перспективе должно обеспечивать надежное и экономически эффективное энерго-, топливоснабжение потребителей с учетом межрегиональных и экспортных энергетических связей восточных регионов со странами Северо-Восточной Азии (СВА) [24].

В процессе исследований развития ТЭК восточных регионов России используются экономико-математические модели, позволяющие разрабатывать ретроспективные и прогнозные топливно-энергетические балансы восточных регионов, которые используются для определения показателей энергоэффективности экономики. Анализ ретроспективных ТЭБ позволяет выявить имеющиеся в ТЭК проблемы и улучшить качество прогноза его развития. С помощью системного анализа определяется энергетический потенциал восточных регионов, необходимый для разработки прогнозных балансов.

${ }^{2}$ В сводном ТЭБ все виды топливно-энергетических ресурсов из натуральных единиц (тонны, кВт·ч, Гкал, м3), через калорийные коэффициенты переводятся в единицы условного топлива (у.т.)

\section{Baikal Research Journal}




\section{Методическая часть}

Методический подход к изучению развития ТЭК восточных регионов России, с использованием балансовых и статистических методов, разработанный авторами, развивает теоретические положения исследований российских и зарубежных ученых в данной предметной области, а также учитывает политику Правительства РФ в сфере экономики и энергетики.

Предложенный авторами методический подход базируется на [2; 3]:

- системе моделей и базе данных для анализа и прогнозирования альтернативных сценариев развития ТЭК Сибири и Дальнего Востока (с подробными сведениями о ТЭК субъектов РФ на этих территориях) с учетом межрегиональных и международных поставок;

- экономико-математических моделях ТЭБ (отдельных видов ТЭР и сводных);

- методах оценки энергоэффективности экономики на основе ТЭБ;

- методах статистического анализа для выявления наиболее значимых факторов, влияющих на энергоэффективность экономики регионов и прогнозирования их динамики на долгосрочную перспективу.

Исследование развития ТЭК восточных регионов России осуществляется по схеме, представленной на рис. 1.

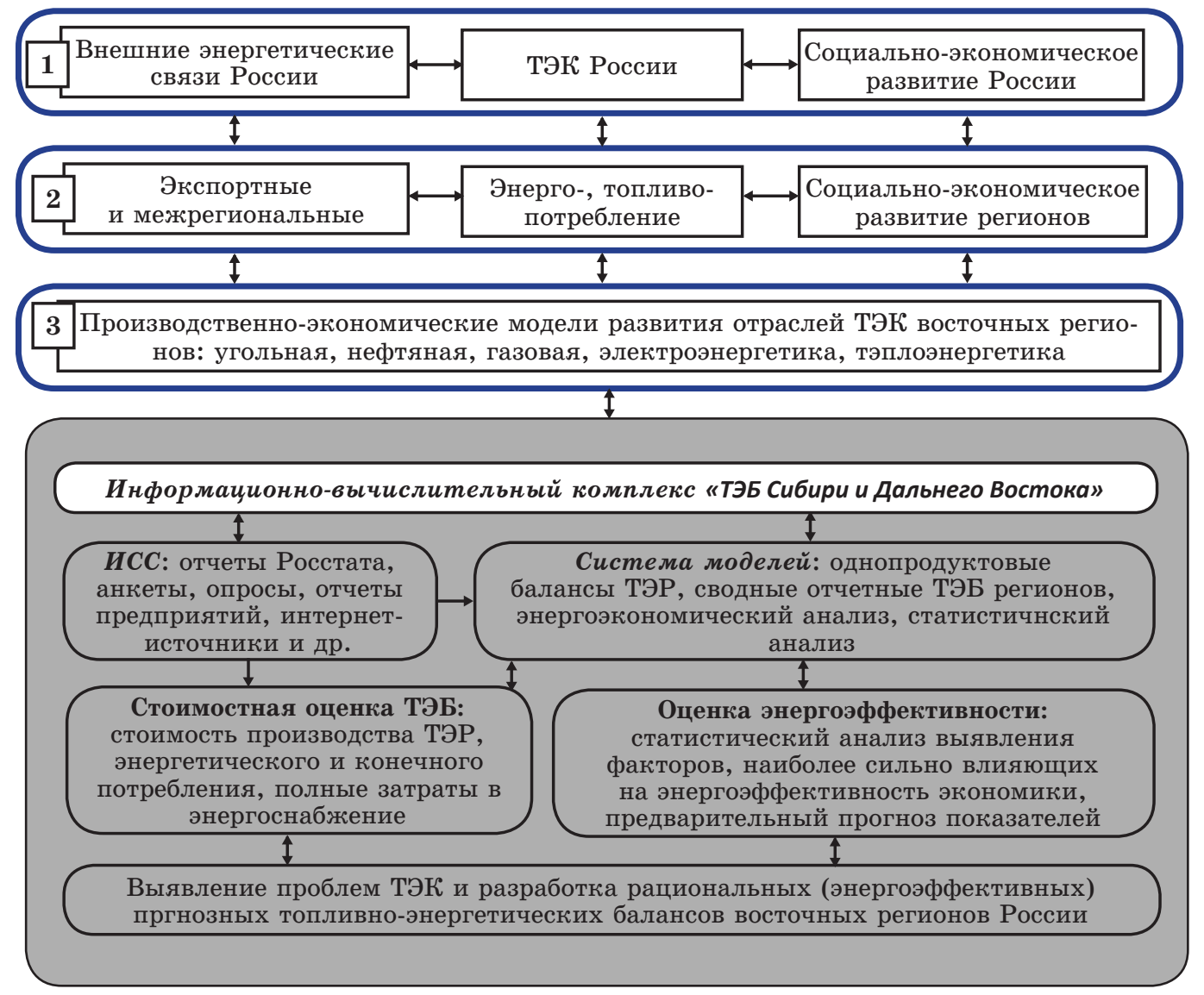

Рис. 1. Схела исследования процессов развития ТЭК восточных регионов и оценки энергоэффективности

\section{Baikal Research Journal}

электронный научный журнал Байкальского государственного университета 
Исследование энергоэффективности базируется на информации, полученной в моделях трех уровней (см. рис. 1): модели федерального уровня: внешних энергетических связей России, ТЭК России, социально-экономического развития России; модели регионального уровня: экспортных и межрегиональных энергетических связей восточных регионов, энерго-, топливопотребления восточных регионов, социально-экономического развития восточных регионов; модели отраслевого уровня: производственно-экономические модели развития отраслей ТЭК восточных регионов: угольная, нефтяная, газовая, электроэнергетика, теплоэнергетика.

При разработке прогнозных ТЭБ показатели, рассчитанные в моделях трех уровней - федерального, регионального и отраслевого, передаются в информационно-вычислительный комплекс (ИВК) («ТЭБ Сибири и Дальнего Востока»), который включает информационно-справочную систему (ИСС) и систему моделей (см. рис. 1).

В ИСС на основе статистической информации формируется база данных исследования. Система моделей ИВК «ТЭБ Сибири и Дальнего Востока» включает экономико-математические модели однопродуктовых балансов отдельных видов ТЭР, сводных топливно-энергетических балансов субъектов РФ на территории Сибирского и Дальневосточного федеральных округов (СФО и ДФО), а также самих макрорегионов, модели энергоэкономического анализа и модели статистического анализа факторов, влияющих на энергоэффективность, модели прогноза показателей энергоэффективности.

Энергоэкономический анализ на основе ретроспективных ТЭБ позволяет выявить характерные особенности и проблемы ТЭК, каждого исследуемого региона, для решения проблем формируется комплекс мер, с учетом роста энергоэффективности, и разрабатываются прогнозы развития ТЭК восточных регионов России.

\section{Анализ энергоэффективности восточных регионов России}

$\mathrm{C}$ использованием разработанного инструментария выполнен анализ современного состояния ТЭК восточных регионов России. ТЭБ восточных регионов России за 2017 г. в виде энергетических потоков представлен на рис. 2.

Анализ энергетических потоков показал, что имеющиеся в восточных регионах ТЭР могут полностью удовлетворить потребности собственных потребителей и обеспечить экспортные поставки. Однако, показатели энергетической, электрической и тепловой емкости ВРП в восточных регионах хуже, чем по России в целом, они выше соответственно - на 28,2; 60 и $39,4 \%$, что характеризует более низкую энергетическую эффективность экономик этих регионов (табл. 1).

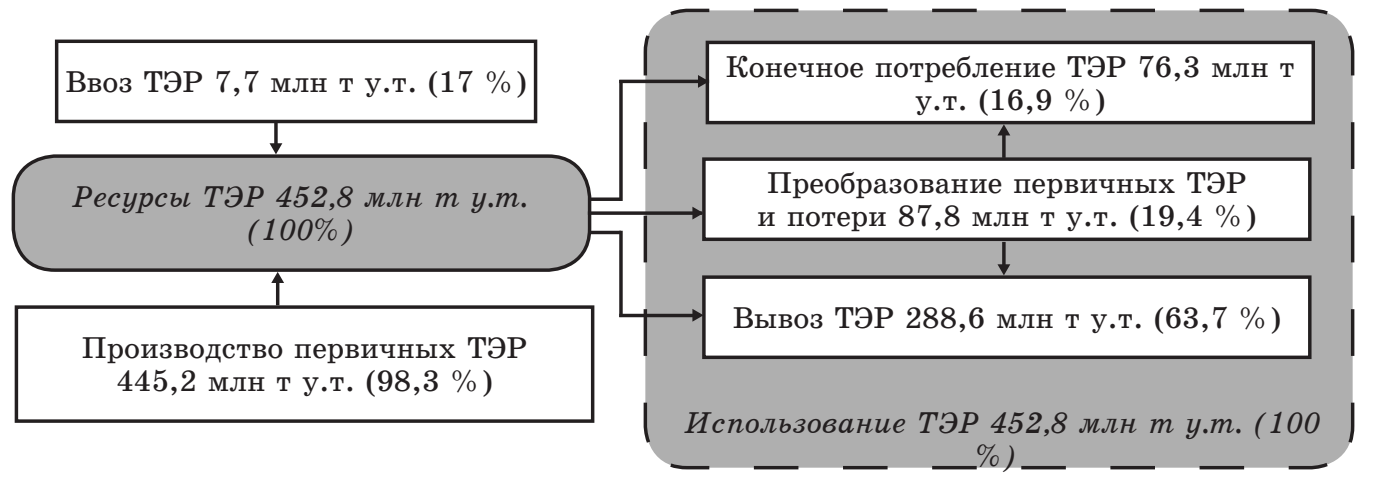

Рис. 2. Схела энергетических потоков в восточных регионах в 2017 г.

\section{Baikal Research Journal}

электронный научный журнал Байкальского государственного университета 
Таблица 1

Показатели энергоэффективности России и ее восточных регионов, 2017 .

\begin{tabular}{|c|c|c|c|c|}
\hline Показатель & Россия & СФО & ДФО & $\begin{array}{c}\text { Восточные } \\
\text { регионы, } \\
\text { в целом }\end{array}$ \\
\hline Энергоемкость ВРП, кг у.т./тыс. р. & 11,0 & 16,2 & 10,0 & 14,1 \\
\hline Электроемкость ВРП, кВт·ч/тыс. p. & 14,5 & 28,6 & 12,6 & 23,2 \\
\hline Теплоемкость ВРП, Гкал/тыс. р. & 17,0 & 27,0 & 17,0 & 23,7 \\
\hline КПИТЭР электростанций, \% & 56,4 & 54,0 & 47,5 & 52,5 \\
\hline КПИТЭР котельных, \% & 85,6 & 75,6 & 71,9 & 74,4 \\
\hline КПИТЭР конечного потребления, \% & 52,7 & 47,5 & 43,3 & 46,5 \\
\hline \multicolumn{5}{|l|}{ Удельный расход топлива на отпуск: } \\
\hline - электроэнергии ТЭС, г у.т./кВт·ч & 304,4 & 346,9 & 373,4 & 353,1 \\
\hline - теплоэнергии ТЭС, кг у.т./Гкал & 156,6 & 159,0 & 156,1 & 158,5 \\
\hline - теплоэнергии котельных, кг у.т./Гкал & 166,6 & 189,1 & 198,8 & 192,3 \\
\hline Потери электроэнергии, млрд кВт·ч & 105,3 & 17,7 & 5,9 & 23,6 \\
\hline - доля потерь от отпуска, \% & 10,3 & 8,5 & 13,3 & 9,6 \\
\hline $\begin{array}{l}\text { Потери теплоэнергии в магистральных } \\
\text { сетях, млн Гкал }\end{array}$ & 94,0 & 19,6 & 7,3 & 26,9 \\
\hline - доля потерь от отпуска, \% & 8,0 & 10,3 & 12,5 & 10,8 \\
\hline
\end{tabular}

Источник - данные Росстата и оценки авторов.

Использование ТЭР в энергетике и экономике восточных регионов менее эффективно, чем в среднем по России. Об этом свидетельствуют коэффициенты полезного использования ТЭР (КПИ в конечном потреблении и на тепловых электростанциях (ТЭС), на 11,2; 6,2 и 3,9 процентных пункта ниже среднероссийских показателей соответственно.

Большинство технологических показателей энергоэффективности энергетики в восточных регионах - удельные расходы топлива и потери ТЭР превышают соответствующие среднероссийские показатели. В 2017 г. удельный расход топлива на отпуск:

- электроэнергии от ТЭС на 16 \% выше, чем в среднем по России;

- тепла от котельных на 15,4 \% выше;

- тепла от ТЭС на 1,2 \% выше.

Удельный вес потерь тепла в магистральных сетях относительно его отпуска на 2,8 процентных пункта выше в восточных регионах.

Более благополучным по сравнению с общероссийским показателем является удельный вес потерь электроэнергии относительно ее отпуска, который в восточных регионах на 0,7 процентный пункт меньше. Это объясняется более низкими потерями электроэнергии в сетях в восточных регионах, доля которых в общих потерях электроэнергии в 2017 г. составила 86,4 \% , в стране в целом этот показатель выше - 91,2 \%, что характеризует лучшее техническое состояние электросетей в этих регионах.

За период 2005-2017 гг. производство первичных ТЭР в восточных регионах увеличилось более чем в 2 раза (табл. 2), чему способствовал рост добычи угля и углеводородов и это же, в основном, обеспечило увеличение в 5,7 раза вывоза ТЭР из этих регионов в другие регионы России и на экспорт. За исследуемый период в связи с сокращением спроса (за счет снижения промышленного производства) снизилось производство энергоносителей - на 11 \% и конечное потребление топлива и энергии - на $3 \%$.

За период 2005-2017 гг. энергоемкость ВРП восточных регионов (в ценах 2017 г.) снизилась на $32 \%$.

\section{Baikal Research Journal}

электронный научный журнал Байкальского государственного университета 
Таблица 2

Диналика статей ТЭБ и энергоемкости ВРП восточных регионов России

\begin{tabular}{|c|c|c|c|c|c|c|c|c|c|c|}
\hline \multirow{2}{*}{ Показатель } & \multicolumn{9}{|c|}{ Год } & \multirow{2}{*}{$\begin{array}{c}2017 / \\
2005\end{array}$} \\
\hline & 2005 & 2010 & 2011 & 2012 & 2013 & 2014 & 2015 & 2016 & 2017 & \\
\hline $\begin{array}{l}\text { Производство } \\
\text { первичных } \\
\text { ТЭР, } \\
\text { млн т у.т. }\end{array}$ & 214,3 & 320,2 & 341,2 & 366,9 & 375,6 & 377,0 & 391,2 & 419,9 & 445,2 & 2,08 \\
\hline $\begin{array}{l}\text { Ввоз ТЭР, } \\
\text { млн т у.т. }\end{array}$ & 13,5 & 12,1 & 12,3 & 11,9 & 11,5 & 11,2 & 10 & 9,1 & 7,7 & 0,57 \\
\hline $\begin{array}{l}\text { Вывоз ТЭР, } \\
\text { млн т у.т. }\end{array}$ & 51,0 & 161,4 & 184,5 & 202,7 & 215,8 & 220,3 & 235,5 & 265,6 & 288,6 & 5,66 \\
\hline $\begin{array}{l}\text { Расход пер- } \\
\text { вичных ТЭР } \\
\text { на преобразо- } \\
\text { вание, } \\
\text { млн т у.т. }\end{array}$ & 98,3 & 97,8 & 94,1 & 99,1 & 91 & 85,9 & 87 & 89,5 & 87,8 & 0,89 \\
\hline $\begin{array}{l}\text { Конечное } \\
\text { потребление } \\
\text { ТЭР, } \\
\text { млн т у.т. }\end{array}$ & 78,5 & 73,1 & 74,9 & 77 & 80,3 & 82 & 78,7 & 73,9 & 76,3 & 0,97 \\
\hline $\begin{array}{l}\text { ВРП в ценах } \\
2017 \text { г., } \\
\text { млрд р. }\end{array}$ & 8575 & 10491 & 11026 & 11187 & 11308 & 11500 & 11435 & 11469 & 11636 & 1,36 \\
\hline $\begin{array}{l}\text { Энергоемкость } \\
\text { ВРП, кг у.т. / } \\
\text { тыс. р. }\end{array}$ & 20,6 & 16,3 & 15,3 & 15,7 & 15,1 & 14,6 & 14,9 & 14,2 & 14,1 & 0,68 \\
\hline
\end{tabular}

Источник - оценки авторов.

На основе анализа ретроспективных ТЭБ выявлен ряд проблем, имеющихся в ТЭК восточных регионов, наиболее важными из которых на сегодняшний день являются следующие:

ухудшение технико-экономических показателей в отраслях ТЭК, рост потерь топлива и энергии, что обусловлено в основном старением основных производственных мощностей и решение этой проблемы требует масштабных затрат на технологические инновации;

наличие значительной доли угля в топливных балансах ТЭС и котельных восточных регионов, приводит к росту расходов топлива и ухудшает экологическую ситуацию, эта проблема может быть решена за счет сокращения доли угля и увеличения доли природного газа и возобновляемых ресурсов у потребителей ТЭР;

более низкие показатели энергоэффективности в восточных регионах по сравнению со страной в целом указывают на имеющийся здесь большой потенциал для их роста, решение этой проблемы связано, в основном с реализацией профильных энергетических программ и региональных программ энергосбережения.

\section{Прогноз энергоемкости ВРП восточных регионов и затрат на технологические инновации}

В рамках исследования выполнен долгосрочный прогноз динамики энергоемкости ВРП восточных регионов России. Для этого проанализирована зависимость изменения энергоемкости ВРП от изменения величин наиболее коррелируемых производственных показателей ТЭК и величины ВРП за период 2005-2017 гг. (см. табл. 2) и разработано уравнение энергоемкости:

\section{Baikal Research Journal}




$$
Y=23,133+0,088 \cdot X_{1}-0,086 \cdot X_{2}-0,0002 \cdot X_{3},
$$

где $Y$ - энергоемкость ВРП; $X_{1}$ - производство первичных ТЭР; $X_{2}$ - вывоз ТЭР; $X_{3}-$ ВРП в ценах 2017 г.

Для разработки уравнения (1), использован метод наименьших квадратов, позволяющий определить аналитическое выражение взаимосвязи результативного признака (в данном случае энергоемкости ВРП) и его факторов (производства первичных ТЭР, вывоза ТЭР, объема ВРП).

С использованием уравнения (1) выполнен прогноз энергоемкости ВРП восточных регионов России до 2050 г. для умеренного и оптимистического сценарием развития экономики и ТЭК. В процессе исследований учтена реализация инновационных мероприятий, позволяющих снизить нерациональное потребление ТЭР. В соответствии с ранее выполненными прогнозами для прогностических расчетов энергоемкости ВРП приняты следующие условия:

- производство первичных ТЭР в восточных регионах увеличится по сравнению с 2017 г.: в умеренном сценарии к 2030 г. - на 13-22 \% , к 2040 г. - на 23$37 \%$, к 2050 г. - на 24-40\% (табл. 3), в оптимистическом сценарии к 2030 г. на $42-60 \%$, к 2040 г. - на 61-89\%, к 2050 г. — в 1,7-1,9 раза (табл. 4);

- вывоз ТЭР возрастет по сравнению с 2017 г.: в умеренном сценарии к 2030 г. - на 19-30\%, к 2040 г. - на 31-47\%, к 2050 г. - на $33-53 \%$, в оптимистическом сценарии к 2030 г. - в 1,6-1,8 раза, к 2040 г. - в $1,7-2,1$ раза, к 2050 г. - в 1,8-2,2 раза;

- ВРП увеличится по сравнению с 2017 г.: в умеренном сценарии к 2030 г. на $15-25 \%$, к 2040 г. - на $25-35 \%$, к 2050 г. - на $35-40 \%$, в оптимистическом сценарии к 2030 г. - на 26-36\%, к 2040 г. - в 1,5-1,6 раза, к 2050 г. - в $1,6-1,7$ раза.

Подставляя исходные параметры в уравнение (1), получим прогнозные значения энергоемкости ВРП. Снижение показателя по сравнению с 2017 г. составит: в умеренном сценарии - 25-45\% к 2030 г., 48-63\% к 2040 г. и $72-93 \%$ к 2050 г. (табл. 3), а в оптимистическом сценарии - 30-57 \% к 2030 г., в 1,7-2,2 раза к 2040 г. и в $1,9-2,8$ раза к 2050 г. (табл. 4).

Таблица 3

Прогноз энергоемкости ВРП восточных регионов", улеренный сценарий

\begin{tabular}{|c|c|c|c|c|c|c|c|c|}
\hline Год & \multicolumn{2}{|c|}{$\begin{array}{c}\text { Производство пер- } \\
\text { вичных ТЭР, } \\
\text { млн т у.т. }\end{array}$} & \multicolumn{2}{|c|}{$\begin{array}{c}\text { Вывоз ТЭР, млн } \\
\text { т у.т. }\end{array}$} & \multicolumn{2}{|c|}{ ВРП ${ }^{* *}$, млрд р. } & \multicolumn{2}{|c|}{$\begin{array}{c}\text { Энергоемкость ВРП } \\
\text { кг у.т. / тыс. } \\
\text { у. }\end{array}$} \\
\hline 2017 & \multicolumn{2}{|c|}{445,2} & \multicolumn{2}{|c|}{288,6} & \multicolumn{2}{|c|}{11636,0} & \multicolumn{2}{|c|}{14,1} \\
\hline 2020 & 453,5 & 463,5 & 294,8 & 310,5 & 12020 & 12109 & 13,7 & 13,0 \\
\hline 2025 & 484,3 & 510,7 & 324,5 & 347,3 & 12800 & 13199 & 12,3 & 11,9 \\
\hline 2030 & 503,9 & 544,8 & 342,6 & 375,9 & 13381 & 14545 & 11,3 & 9,7 \\
\hline 2035 & 524,0 & 575,4 & 361,0 & 399,9 & 13964 & 15127 & 10,3 & 9,2 \\
\hline 2040 & 545,7 & 607,8 & 378,6 & 425,5 & 14545 & 15708 & 9,6 & 8,7 \\
\hline 2050 & 550,0 & 620,0 & 38,0 & 440,2 & 15127 & 16290 & 8,2 & 7,3 \\
\hline
\end{tabular}

Примечания:

"левая граница диапазона соответствует более низким показателям, правая - более высоким, но в границах умеренного сценария развития экономики и ТЭК восточных регионов России;

*"ВРП в ценах 2017 г.

Источник - оценки авторов

\section{Baikal Research Journal}

электронный научный журнал Байкальского государственного университета 
Таблица 4

Прогноз энергоелкости ВРП восточных регионов", оптилистический сценарий

\begin{tabular}{|c|c|c|c|c|c|c|c|c|}
\hline Год & \multicolumn{2}{|c|}{$\begin{array}{c}\text { Производство пер- } \\
\text { вичных ТЭР, млн т } \\
\text { у.т. }\end{array}$} & \multicolumn{2}{|c|}{$\begin{array}{c}\text { Вывоз ТЭР, млн } \\
\text { т у.т. }\end{array}$} & \multicolumn{2}{|c|}{ ВРП ${ }^{* *}$, млрд р. } & \multicolumn{2}{|c|}{$\begin{array}{c}\text { Энергоемкость ВРП } \\
\text { кг у.т./тыс. } \\
\text { р. }\end{array}$} \\
\hline 2017 & \multicolumn{2}{|c|}{445,2} & \multicolumn{2}{|c|}{288,6} & \multicolumn{2}{|c|}{11636,0} & \multicolumn{2}{|c|}{14,1} \\
\hline 2020 & 470,9 & 497,4 & 315,5 & 333,3 & 12527 & 13519 & 12,4 & 11,2 \\
\hline 2025 & 570,3 & 607,5 & 399,2 & 431,3 & 13591 & 14668 & 11,9 & 10,2 \\
\hline 2030 & 629,9 & 713,8 & 447,2 & 528,2 & 14654 & 15815 & 10,9 & 9,0 \\
\hline 2035 & 672,5 & 802,6 & 470,8 & 593,9 & 16053 & 17216 & 9,8 & 8,4 \\
\hline 2040 & 715,2 & 839,8 & 500,6 & 621,5 & 17454 & 18618 & 8,2 & 6,5 \\
\hline 2050 & 750,0 & 860,0 & 532,5 & 645,0 & 18036 & 19199 & 7,4 & 5,1 \\
\hline
\end{tabular}

Примечания:

"левая граница диапазона соответствует более низким показателям, правая - более высоким, но в границах оптимистического сценария развития экономики и ТЭК восточных регионов России;

"*ВРП в ценах 2016 г.

Источник - оценки авторов

Достижение динамики снижения энергоемкости ВРП, представленной в таблицах 3 и 4, возможно лишь при увеличении затрат на технологические инновации в восточных регионах России. Ретроспективная динамика затрат на технологические инновации приведена в табл. 5.

Таблица 5

Затраты на технологические инновации в восточных регионах , млрд $р$.

\begin{tabular}{|c|r|r|r|r|r|r|r|r|}
\hline 2005 г. & \multicolumn{1}{|c|}{2010 г. } & \multicolumn{1}{|c|}{2011 г. } & \multicolumn{1}{|c|}{2012 г. } & \multicolumn{1}{|c|}{2013 г. } & \multicolumn{1}{|c|}{2014 г. } & \multicolumn{1}{c|}{2015 г. } & \multicolumn{1}{c|}{2016 г. } & 2017 г. \\
\hline 116,5 & 177,7 & 213,8 & 217,8 & 196,2 & 190,9 & 168,7 & 162,4 & 190,0 \\
\hline
\end{tabular}

Примечание - "в ценах 2017 г.

Источник - рассчитано по данным Росстата

Для определения взаимосвязи инноваций и энергоемкости ВРП разработано уравнение регрессии (2):

$$
Y=25,727-0,054 \cdot X_{4},
$$

где $X_{4}$ - затраты на технологические инновации.

При известных значениях энергоемкости ВРП (табл. 3,4$)$ из уравнения $(2)$ определим значение необходимых затрат на технологические инновации в восточных регионах России в сопоставимых ценах 2017 г. на период 2020-2050 гг. (рис. 3).

Для достижения прогнозной динамики энергоемкости ВРП, согласно расчетам, выполненным с использованием уравнения (2), затраты на технологические инновации в восточных регионах должны возрасти по сравнению с 2017 г.: в умеренном сценарии к 2030 г. - на 41-56 \%, к 2040 г. - на 58-67\%, к 2050 г. на 71-80\%, в оптимистическом сценарии к 2030 г. - на 45-64 \%, к 2040 г. - в $1,7-1,9$ раза, к 2050 г. - в 1,8-2 раза.

\section{Выводы}

Проведенное на базе ИВК «ТЭБ Сибири и Дальнего Востока» исследование показало, что использование ТЭР в восточных регионах менее эффективно, чем в среднем по России. КПИ тэр котельных, конечных потребителей и тепловых

\section{Baikal Research Journal}

электронный научный журнал Байкальского государственного университета 


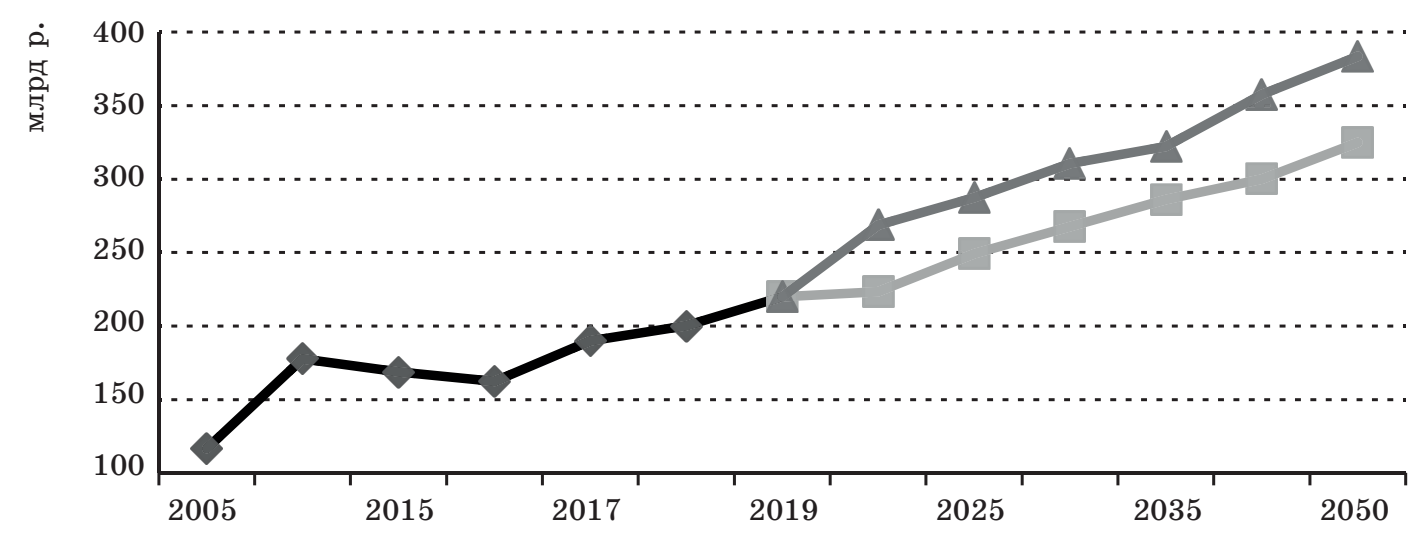

- Фактические затраты на технологические инновации

- Прогноз нижняя граница

- Прогноз верхняя граница

Примечание: нижняя граница расчетного диапазона соответствует нижней границе умеренного сценария, верхняя - верхней границе оптимистического сценария

Рис. 3. Прогноз затрат на технологические инновации в восточных регионах

электростанций на 11,$2 ; 6,2$ и 3,9 процентных пункта ниже среднероссийских показателей соответственно. Удельные расходы топлива и потери ТЭР превышают соответствующие среднероссийские показатели, что характеризует наличие в восточных регионах большого потенциала роста энергоэффективности экономики.

За период 2005-2017 гг. производство первичных ТЭР увеличилось в 2 раза. Вывоз ТЭР из восточных регионов в другие регионы России и на экспорт увеличился в 5,7 раза. За этот же период снизился расход первичных ТЭР на преобразование - на $11 \%$ и конечное потребление ТЭР - на $3 \%$.

Энергоемкость ВРП восточных регионов снизилась с 2005 г. по 2017 г. на $32 \%$, однако этому способствовали в основном структурные сдвиги в экономике (снижение доли энергоемких производств). Для устойчивого социально-экономического развития восточных регионов необходим рост энергоэффективности экономики на базе технологических факторов. Особое место в решении этой проблемы будет играть ТЭК и в частности улучшение структуры ТЭБ в направлении роста доли природного газа и возобновляемых ресурсов в доходах и расходах, увеличении доли переработки ТЭР, сокращении потерь энергоресурсов.

Основными путями улучшения структуры ТЭБ восточных регионов являются:

- снижение доли угля за счет роста доли природного газа и возобновляемых ресурсов, что позволит удовлетворить спрос на энергоносители при меньших удельных расходах топлива и снизить антропогенное воздействие на окружающую среду;

- строительство нефте-, газоперерабатывающих заводов в регионах с крупными запасами углеводородов (например, в Иркутской области, республике Саха (Якутия)), что позволит производить углеводородную продукцию с более высокой добавленной стоимостью и повысить бюджетную наполняемость;

- сокращение потерь ТЭР в процессе их производства, транспортировки и потребления;

\section{Baikal Research Journal}

электронный научный журнал Байкальского государственного университета 
- эффективное использование местных видов топлива и возобновляемых источников энергии для потребителей в отдаленных районах с целью повышения надежности энергоснабжения и снижения потерь энергоносителей в сетях;

- увеличение объемов переработки угля в восточных регионах с целью повышения качества и конкурентоспособности угольной продукции и в отдаленной перспективе для производства инновационных продуктов переработки (бездымные топливные брикеты, сельскохозяйственные удобрения и т. д.).

В процессе развития ТЭК восточных регионов России для их устойчивого социально-экономического развития необходим рост энергоэффективности.

Согласно выполненному прогнозу энергоемкость ВРП восточных регионов может снизиться к 2050 г. по сравнению с 2017 г., в умеренном на $72-93 \%$, а в оптимистическом сценарии - в $1,9-2,8$ раза.

Такая динамика снижения энергоемкости ВРП возможна при росте затрат на технологические инновации к 2050 г. по сравнению с 2017 г. в умеренном сценарии в 1,7-1,8 раза, в оптимистическом сценарии - в 1,8-2 раза.

Проблемы ТЭК восточных регионов, могут быть решены только при наличии комплексной, согласованной долгосрочной стратегии энергетической кооперации между регионами в процессе создания общего энергетического рынка с точки зрения экспорта ТЭР в страны СВА. Это позволит рационально использовать имеющийся энергетический потенциал восточных регионов.

\section{Список использованной литературы}

1. Новак А. Энергоэффективность и развитие энергетики [Электронный ресурс] : выступ. Министра энергетики РФ на заседании Правительства РФ / А. Новак. - Режим доступа: http://gisee.ru/law/others/47878/.

2. Топливно-энергетические балансы в системе комплексного исследования развития региональных ТЭК / Б.Г. Санеев [и др.] // Известия Российской академии наук. Энергетика. -2011 . - № 2. - С. 21-35.

3. Энергоэкономический анализ существующего состояния региональных топливноэнергетических комплексов Востока России / Б.Г. Санеев [и др.] // Энергетическая политика. -2016 . - № 5. - С. 14-22.

4. Кржижановский Г.М. Топливно-энергетический баланс / Г.М. Кржижановский, В.И. Вейц, Е.А. Руссаковский // Вестник статистики. - 1932. - № 7. - С. 12-17.

5. Пробст А.Е. Единый энергетический баланс и использование энергоресурсов в СССР / А.Е. Пробст // Электричество. - 1937. - № 24. - С. 4-10.

6. Мелентьев Л.А. Топливно-энергетический баланс СССР / Л.А. Мелентьев, М.А. Стырикович, Е.О. Штейнгауз. - М. : Госэнергоиздат, 1962. - 208 с.

7. Некрасов А.С. Построение и анализ энергетического баланса. Вопросы методологии и методики / А.С. Некрасов, Ю.В. Синяк, В.А. Янпольский. - М. : Энергоатомиздат, 1974. - $178 \mathrm{c}$.

8. Макаров А.А. Топливно-энергетический комплекс. Методы исследования оптимальных направлений развития / А.А. Макаров, А.Г. Вигдорчик. - М. : Наука, 1979. - 279 с.

9. Башмаков И.А. Топливно-энергетический баланс как инструмент анализа, прогноза и индикативного планирования развития энергетики / И.А. Башмаков // Энергетическая политика. - 2007. - № 2. - C. 16-25.

10. Бушуев В.В. Энергоэффективность и экономика России / В.В. Бушуев, А.А. Троицкий // Энергия: экономика, техника, экология. -2004 . - № 5. - С. 10-19.

11. Галиева Т.М. О методологии разработки топливно-энергетических балансов / T.М. Галиева, А.М. Мастепанов // Энергетическая политика. - 2003. - № 3. - С. 21-27.

12. Гашо Е.Г. Формирование региональных программ энергосбережения / Е.Г. Гашо, Е.В. Репецкая, В.Н. Бандурист // Энергосбережение. - 2010. - № 8. - С. 1-14.

13. Топливно-энергетический баланс как инструмент анализа и прогноза взаимодействий экономики и энергетики региона / В.Н. Чурашев [и др.] // Энергетика в глобальном мире : материалы междунар. науч.-тех. конгр., Красноярск, 16-18 июня 2010 г. - Красноярск, 2010. - С. 383-384.

\section{Baikal Research Journal}


14. Chupjatov V. Energy efficiency and savings in the Russia / V. Chupjatov, A. Makarov, E. Medvedeva // International Journal of Global Energy Issues. - 2001. - Vol. 16, no. 1-3. - P. 213-225.

15. Rosenfeld A.H. Real Prospects for Energy Efficiency in the United States / A.H. Rosenfeld. - Washington : The National Academies Press, 2009. - 349 p.

16. Patterson M. What is Energy Efficiency? / M. Patterson // Energy Policy. - 1996. Vol. 24, no. 5. - P. 377-390.

17. Haas R. Energy Efficiency Indicators in the Residential Sector / R. Haas // Energy Policy. - 1997. - Vol. 25, no. 7-9. - P. 789-802.

18. Hotelling H. The Economics of Exhaustible Resources / H. Hotelling // Journal of Political Economy. - 1931. - Vol. 39. - P. 137-175.

19. Solow R.M. The Economics of Resources and the Resources of Economics / R.M. Solow // American Economic Review. - 1974. - Vol. 64, iss. 2. - P. 1-14.

20. Nordhaus W.D. The Efficient Use of Energy Resources / W.D. Nordhaus. - New Haven : Yale University, 1979. - 161p.

21. Chandler M. Natural Resources as a Constraint on Economic Growth: Discussion / M. Chandler // The American Economic Review. - 1973. - Vol. 63, iss. 2. - P. 126-128.

22. Lakshmanan T.R. Integrated Models for Economic-Energy-Environmental Impact Analysis / T.R. Lakshmanan, S. Ratick // Economic-Environmental-Energy Interactions: Modeling and Policy Analysis / ed. T.R. Lakshmanan, P. Nijkamp. - Hardcover : Springer, 1980. - P. 7-39.

23. Energy Efficiency and Sustainable Consumption: The Rebound Effect / ed. H. Herring, S. Sorrel. - Hampshire : Palgrave Macmillan, 2009. - 266 p.

24. Лузянин С. Северо-Восточная Азия (CBА) - субрегион, в который входят Япония, Северная и Южная Кореи, Монголия, Китай (КНР) и Тайвань [Электронный ресурс] / C. Лузянин. - Режим доступа: http://www.perspektivy.info/book/severo-vostochnaja_ azija_vnutrennije_i_vneshnije_izmerenija_razvitija_i_bezopasnosti_2012-03-07.htm.

\section{References}

1. Novak A. Energy efficiency and development of energetics. Available at: http://gisee. $\mathrm{ru} /$ law/others/47878/. (In Russian).

2. Saneev B.G., Sokolov A.D., Muzychuk S.Yu., Muzychuk R.I. Energy Balances in the System of Complex Studies on Development of Regional fuel and Energy Complexes. Izvestiya Rossiiskoi akademii nauk. Energetika = Proceedings of the Russian Academy of Sciences. Power Engineering, 2011, no. 2, pp. 21-35. (In Russian).

3. Saneev B.G., Sokolov A.D., Muzychuk S.Yu., Muzychuk R.I. Energy-economic Analysis of the Current State of the Regional fuel and Energy Complexes of the Russian East. Energeticheskaya politika = Energy Policy, 2016, no. 5, pp. 14-22. (In Russian).

4. Krzhizhanovsky G.M., Veits V.I., Russakovsky E.A. Energy balance. Vestnik statisti$k i=$ Bulletin of Statistics, 1932, no. 7, pp. 12-17. (In Russian).

5. Probst A.E. Overall Energy Balance and Energy Resource Usage in the USSR. Elektrichestvo $=$ Electricity, 1937, no. 24, pp. 4-10. (In Russian).

6. Melentev L.A., Styrikovich M.A., E.O. Shteingauz E.O. Toplivno-energeticheskii balans SSSR [Fuel and energy balance of the USSR]. Moscow, Gosenergoizdat Publ., 1962. 208 p.

7. Nekrasov A.S., Sinyak Yu.V., Yanpolsky V.A. Postroyeniye $i$ analiz energeticheskogo balansa. Voprosy metodologii $i$ metodiki [Building and analysis of the energy complex. Issues of methodology and methods]. Moscow, Energoatomizdat Publ., 1974. 178 p.

8. Makarov A.A., Vigdorchik A.G. Toplivno-energeticheskiy kompleks. Metody issledovaniya optimal'nykh napravleniy razvitiya [Fuel and energy complex. Methods of investigation of optimal development directions]. Moscow, Nauka Publ., 1979. 279 p.

9. Bashmakov I.A. Fuel and energy balance as an instrument of analyzing, forecasting and indicative planning the development of energetics. Energeticheskaya politika = Energy Policy, 2007, no. 2, pp. 16-25. (In Russian).

10. Bushuev V.V., Troitsky A.A. Energy Efficiency and the Russian Economy. Energiya: ekonomika, tekhnika, ekologiya = Energy: Economics, Technology, Ecology, 2004, no. 5, pp. 10-19. (In Russian).

\section{Baikal Research Journal}


11. Galieva T.M., Mastepanov A.M. About Methodology of Development of Fuel and Energy Balances. Energeticheskaya politika = Energy Policy, 2003, no. 3, pp. 21-27. (In Russian).

12. Gasho E.G., Repetskaya E.V., Bandurist V.N. Formation of Regional Programs of Energy Saving. Energosberezhenie = Energy Saving Technologies, 2010, no. 8, pp. 1-14. (In Russian).

13. Churashev V.N., Suslov N.I., Markova V.M., Chernova G.V. Fuel and energy balance as an instrument of analyzing and forecasting the interactions of regional economy and energetics. Energetika $v$ global'nom mire. Materialy mezhdunarodnogo nauchno-tekhnicheskogo kongressa, Krasnoyarsk, 16-18 iyunya 2010 g. [Energy in the Global World. Materials of the International Scientific and Technical Congress, Krasnoyarsk, June, 16-18, 2010]. Krasnoyarsk, 2010, pp. 383-384. (In Russian).

14. Chupjatov V., Makarov A., Medvedeva E. Energy efficiency and savings in the Russia. International Journal of Global Energy Issues, 2001, vol. 16, no. 1-3, pp. 213-225.

15. Rosenfeld A.H. Real Prospects for Energy Efficiency in the United States. Washington, The National Academies Press, 2009. 349 p. 390 .

16. Patterson M. What is Energy Efficiency? Energy Policy, 1996, vol. 24, no. 5, pp. 377-

17. Haas R. Energy Efficiency Indicators in the Residential Sector. Energy Policy, 1997, vol. 25 , no. 7-9, pp. 789-802.

18. Hotelling H. The Economics of Exhaustible Resources. Journal of Political Economy, 1931, vol. 39, pp. 137-175.

19. Solow R.M. The Economics of Resources and the Resources of Economics. American Economic Review, 1974, vol. 64, iss. 2, pp. 1-14.

20. Nordhaus W.D. The Efficient Use of Energy Resources. New Haven, Yale University Press, 1979. - 161p.

21. Chandler M. Natural Resources as a Constraint on Economic Growth: Discussion. The American Economic Review, 1973, vol. 63, iss. 2, pp. 126-128.

22. Lakshmanan T.R., Ratick S. Integrated Models for Economic-Energy-Environmental Impact Analysis. In Lakshmanan T.R., Nijkamp P. (eds). Economic-Environmental-Energy Interactions: Modeling and Policy Analysis. Hardcover, Springer, 1980, pp. 7-39.

23. Herring H., Sorrel S. (eds). Energy Efficiency and Sustainable Consumption: The Rebound Effect. Hampshire, Palgrave Macmillan, 2009. 266 p.

24. Luzyanin S. North-Eastern Asia (NEA), a sub-region including Japan, North and South Korea, Mongolia, China (Peoples' Republic of China) and Taiwan. Available at: http://www. perspektivy.info/book/severo-vostochnaja_azija_vnutrennije_i_vneshnije_izmerenija_razvitija_i_bezopasnosti_2012-03-07.htm. (In Russian).

\section{Информация об авторах}

Санеев Борис Григорьевич - доктор технических наук, заведующий отделом, руководитель научного направления «Комплексные проблемы энергетики и региональная энергетическая политика», Институт систем энергетики им. Л.А. Мелентьева Сибирского отделения Российской академии наук, Российская Федерация, г. Иркутск, e-mail: saneev@isem.irk.ru.

Соколов Александр Даниилович - доктор технических наук, главный научный сотрудник, Институт систем энергетики им. Л.А. Мелентьева Сибирского отделения Российской академии наук, Российская Федерация, г. Иркутск, e-mail: sokolov@isem.irk.ru.

Музычук Светлана Юрьевна - кандидат экономических наук, ведущий научный сотрудник, Институт систем энергетики им. Л.А. Мелентьева Сибирского отделения Российской академии наук, Российская Федерация, г. Иркутск, e-mail: muz@isem.irk.ru.

Музычук Ролан Игоревич - ведущий инженер, Институт систем энергетики им. Л.А. Мелентьева Сибирского отделения Российской академии наук, Российская Федерация, г. Иркутск, e-mail: rmuz@isem.irk.ru.

\section{Authors}

Boris G. Saneev - Doctor habil. in Engineering, Head of Department, Supervisor of Research "Complex Problems of Energy and Regional Energy Policy", L.A. Melentyev Institute

\section{Baikal Research Journal}


of Energy Systems Institute of Siberian Branch of the Russian Academy of Sciences, Irkutsk, Russian Federation, e-mail: saneev@isem.irk.ru.

Alexander D. Sokolov - Doctor habil. in Engineering, Chief Researcher, L.A. Melentyev Energy Systems Institute of Siberian Branch of the Russian Academy of Sciences, Irkutsk, Russian Federation, e-mail: sokolov@isem.irk.ru.

Svetlana Yu. Muzychuk - Ph.D. in Economics, Leading Researcher, L.A. Melentyev Energy Systems Institute of Siberian Branch of the Russian Academy of Sciences, Irkutsk, Russian Federation, e-mail: muz@isem.irk.ru.

Roman I. Muzychuk - Senior Engineer, L.A. Melentyev Energy Systems Institute of Siberian Branch of the Russian Academy of Sciences, Irkutsk, Russian Federation, e-mail: rmuz@isem.irk.ru.

\section{Для цитирования}

Санеев Б.Г. Рост энергоэффективности - путь к устойчивому развитию экономики восточных регионов России / Б.Г. Санеев, А.Д. Соколов, С.Ю. Музычук, Р.И. Музычук // Baikal Research Journal. — 2019. — T. 10, № 2. — DOI : 10.17150/2411-6262.2019.10(2).11.

\section{For Citation}

Saneev B.G., Sokolov A.D., Muzychuk S.Yu., Muzychuk R.I. Growth of Energy Efficiency is the Road to Sustainable Development of Economy of Russia's Eastern Regions. Baikal Research Journal, 2019, vol. 10, no. 2. DOI: 10.17150/2411-6262.2019.10(2).11. (In Russian).

\section{Baikal Research Journal}

